\title{
Yönetici ve Öğretmenlerin Öğrencilerden Beklentileri ve Öğrencilerin Bu Beklentileri Algılayış Biçimleri
}

\author{
DOI: 10.26466/opus.705266
}

\author{
*

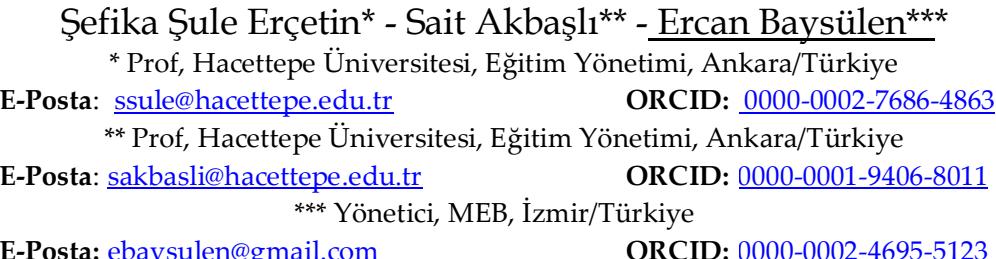

Öz

Bu çalışmada, ĕgitim-öğretimin kalitesini ve etkililiğini artırmak amacıyla, öğretmenlerin ve okul yöneticilerinin öğrencilerden beklentilerinin neler olduğunun ayn zamanda bu beklentilerin ortaöğretim 9,10,11 ve 12. sını öğrencileri tarafından nasıl algılandığının belirlenmesi amaçlanmıştır. Bu amaçtan yola çıkarak eğitim sisteminin en önemli parçası olan öğrencilerin; öğretmenlerinin ve okul idaresinin kendilerinden beklentilerinin neler olduğunu algılama biçimleri, bu algılayışın öğretmen ve yöneticilerin gerçek beklentileriyle tutarlllı gösterip göstermediği ve bu doğrultuda yaşanan problemler görüşmeler yoluyla tespit edilmeye çalışılmıştır. Çalı̧̧madan elde edilen bulgular; öğretmenlerin ögrencilerden derse hazırlıkl gelmeleri, derse aktif olarak katılmalar, verilen görevleri yerine getirmeleri ve sorumluluk sahibi, erdemli bireyler olmaları şeklindeyken, okul yöneticilerinin başarıll, okul kurallarına uyan, ahlaklı, erdemli bireyler olmaları şeklinde beklentileri olduğu görülmüştür. Öğrencilerse öğretmenlerin kendilerinden çalışkan ve başarılı olmalarını, derslere hazırlıkl gelmelerini, ders sırasında derse katılmalarını, katılmadıkları zamanlarda konuşmadan sessiz durmaların beklediklerini belirtmişlerdir. Ayrıca öğretmenler kendilerinden iyi not almaların, başarısız oldukları derslerde ise en azından geçer not almalarım beklediklerini belirtmişlerdir. İarecilerin kendilerinden disiplinli olmalarını, okulun kurallarına uymalarını, çalışkan ve başarılı olmalarını, çevreye zarar vermemelerini, okula bă̧̧̆̆ yapmalarını, sigara içmemelerini beklediklerini belirtmişlerdir. Bazı öğrenciler ise kendilerinin gelişimleriyle ilgili idarenin sorumlu olmadığını, idarenin kendilerinden başarı beklentilerinin olmadığıı bu beklentinin ders öğretmenleri dışında okulun rehberlik birimi tarafindan olduğunu belirtmişlerdir.

Anahtar Kelimeler: Öğretmen Beklentisi, Yönetici Beklentisi, Öğrenci Algısı. 


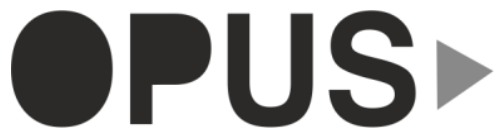

Uluslararası Toplum Araştırmaları Dergisi International Journal of Society Researches
E-ISSN : 2528-9535

YIl Year: 10

Cilt Volume: 16

Sayı Issue :Eğitim ve Toplum Özel Sayısı

Aralık December 2020

Makalenin Geliş Tarihi Received Date: 17/03/2020

Makalenin Kabul Tarihi Accepted Date: 29/12/2020

\title{
Managers' and Teachers' Expectations from Students and Students' Perception of These Expectations
}

\begin{abstract}
In this study, it was aimed to determine what the expectations of teachers and school administrators were from students and how these expectations were perceived by the students in order to increase the quality and effectiveness of education and to develop sensitive practices. Findings obtained without working; it has been seen that teachers are expected to be successful, to be school rules, to be moral, virtuous individuals when they are ready to learn from the lessons, actively participate in the lessons and fulfill their assigned duties and responsibilities and be virtuous individuals. On the other hand, the students stated that the teachers were expected to be hardworking and successful, to be prepared for the lessons, to attend the class during the lesson and to be silent without speaking if they did not participate. In addition, the teachers stated that they should take good grades from themselves and at least they should wait for passing grades in the courses they fail. They stated that administrators should be disciplined, obey school rules, be diligent and successful, do not harm the environment, donate to school, and expect to smoke and that they were not responsible for their social and academical development.
\end{abstract}

Keywords: Teacher Expectant, Manager Expectant, Student Perception 


\section{Giriş}

Beklenti, önceki deneyimlerden yola çıkarak gelecekte ne olabileceği ile ilgili çıkarımlarda bulunmaktır. Öğretmen beklentisi, öğretmenin, bildiklerinden yola çıkarak öğrencinin şimdiki ve gelecekteki okul başarısı ve sınıf davranışı hakkında yaptığı çıkarımlardır (Brophy, 1998). Öğretmenin öğrencisinin kapasitesine yönelik sahip olduğu inanç öğretmenin öğrenciden beklentisini oluşturur. Bir öğrenci hakkında olumlu beklentileri olan öğretmen, daha olumlu sosyo-duygusal bir etki gösterir; daha fazla gülümser, ses tonuyla ve yüz ifadeleriyle daha sıcak bir tavır sergiler. Benzer şekilde, olumlu beklentileri olan öğretmenler, öğrencilerine öğretebilmek için daha fazla çaba sarf eder; daha fazla konu öğretir, öğrenciyle daha fazla zaman geçirir ve daha zor konuları öğretirler (Harris, Milich ve McAninch, 1998). Rosenthal ve Jacobson (1968)'un çalısmalarında, öğretmenlerin daha yüksek başarı beklentisi geliştirdikleri öğrencilere daha uygun bir sosyal ve duygusal ortam oluşturmalarının öğrencilerin başarılarını artırdığını göstermiştir. Brophy ve Good (1969) da öğretmen beklentisinin, kendini doğrulayan kehanete nasıl dönüştüğünü gösteren bir model geliştirmişlerdir. Öztürk ve arkadaşlarının yaptığı araştırmada da (2002a) öğretmenlerin yüksek beklenti içerisinde olduğu öğrencilere daha çok etkileşime girdiği bulgularına ulaşılmıştır. Araştırmalarda öğretmenlerin öğrencilerine yönelik geliştirdikleri beklentilerin öğrencilere davranışlarını etkilediğinin her zaman farkında olmasalar da ilköğretim çağındaki öğrencilerin bile bunun farkında oldukları belirtilmektedir (Weinstein and Mckown, 1998; Tatar, 2014). Alanyazında öğretmenlerin öğrencilerinden beklentilerinin öğrenci başarısı için önemli olduğuna yönelik çalışmalar bulunmasına rağmen öğrencilerin bu beklentilerin farkında olup olmadıklarına yönelik çalışmaların azlığı dikkat çekmektedir. Bir eğitim kurumunda öğrencilerin başarısını ve eğitimdeki kaliteyi artırmada öğrencilerin, öğretmenlerin ve okul yöneticilerinin kendilerinden neler beklediğinin farkında olmasının önemli olduğu düşünülmektedir. Bu noktada sınıf içinde öğretmenlerin beklentilerini ve öğrencilerin bunları nasıl algıladığını ortaya koyma noktasında bu araştırma önemli görülmektedir. Bu çalışmada, eğitim-öğretimin kalitesini ve etkililiğini arttırmak amacryla, öğretmenlerin ve okul yöneticilerinin öğrencilerden beklentilerinin neler olduğunun aynı zamanda bu beklentilerin ortaöğretim 9,10,11 ve 12 . sınıflarda öğrenim gören öğrenciler tarafından nasıl algılandığının belir- 
lenmesi amaçlanmıştır. Bu amaçtan yola çıkarak eğitim sisteminin en önemli parçası olan öğrencilerin; öğretmenlerinin ve okul idaresinin kendilerinden beklentilerinin neler olduğunu algılama biçimleri, bu algılayışın öğretmen ve yöneticilerin gerçek beklentileriyle tutarllık gösterip göstermediği ve bu doğrultuda yaşanan problemler görüşmeler yoluyla tespit edilmeye çalışılmıştır. Bu araştırmanın temel sorusu "Yönetici ve öğretmenlerin öğrencilerden beklentileri ve öğrencilerin bu beklentileri algılayış biçimleri nasıldır?" şeklinde ifade edilebilir. Ayrıca aşağıdaki alt problemlere de cevap aranmiştır:

1. Öğretmenlerin öğrencilerden beklentileri nelerdir?

2. Öğretmenlerin beklentileri öğrencilerinin davranış, akademik/sosyal başarı gibi durumlarına göre değişiklik göstermekte midir?

3. Okul yöneticilerin öğrencilerden beklentileri nelerdir?

4. Okul yöneticilerinin beklentileri öğrencilerinin davranış, akademik/sosyal başarı gibi durumlarına göre değişiklik göstermekte midir?

5. Öğrencilerin, öğretmenlerinin kendilerinden beklentilerini algılayış biçimleri nasıldır?

6. Öğrencilerin, okul yöneticilerinin kendilerinden beklentilerini algılayış biçimleri nasıldır?

\section{Yöntem}

$\mathrm{Bu}$ çalışma nitel araştırma yöntemi kullanılarak gerçekleştirilmiştir. Nicel çalışmalar ile karşılaştırıldığında, nitel çalışmalar derinlemesine bilgi, kavrayış ve anlayış sağlamaktadır. Nitel araştırmada, tümevarım ilkesiyle hareket edilir ve incelenen probleme ilişkin toplanan verilere açıklamalar getirilir. Nitel çalışmalarda amaç, sayılar yoluyla genellenebilir sonuçlara ulaşmak değil; araştırılan konu ile ilgili betimsel ve gerçekçi bir resim sunmaktır. Araştırma sonuçlarının geçerlik ve güvenirliği açısından verilerin olabildiğince ayrıntılı ve doğrudan sunulması önemlidir (Yıldırım ve Şimşek, 2006).

\section{Nitel örneklem}

Araştırmanın çalışma grubunu İzmir İli Bayraklı İlçesinde bulunan bir devlet okulunda ortaöğretim 9,10,11 ve 12. sinfflarda bulunan 59 öğrenci, 21 
öğretmen ve bölgede bulunan 9 idareci oluşturmaktadır. Yapılan araştırma gönüllülük esasına dayanılarak yürütülmüştür.

\section{Veri Toplama Aracı ve Verilerin Toplanması}

Bu çalışmada 2018-2019 eğitim öğretim yılında İzmir ili Bayraklı ilçesinde görev yapmakta ola okul yöneticileriyle bir ortaöğretim okulunda görev yapan öğretmenler ve öğrenim görmekte olan 9, 10, 11 ve 12. sinıf öğrencinin görüşlerini belirlemek için açlk uçlu sorulardan oluşan yarı yapılandırılmış görüşme formları kullanılmıştır. Görüşme formları üç uzman görüşü doğrultusunda düzenlenerek son şeklini almıştır. Araştırmacılar katılımcıların tümüyle yüz yüze görüşmüştür. Görüşmeler 5 dakika ile 20 dakika arasinda sürmüştür.

\section{Verilerin Analizi}

Araştırmada öğretmen, yönetici ve öğrenci görüşlerinin analizinde nitel veri analiz tekniklerinden içerik analizi yöntemi kullanılmıştır. İçerik analizinde yapılan işlem, birbirine benzeyen verileri belirli kavramlar ve temalar çerçevesinde bir araya getirmek ve bunları okuyucunun anlayabileceği bir biçimde düzenleyerek yorumlamaktır (Yıldırım ve Şimşek, 2006). Verilerin analizinde öğretmenlerden toplanan veriler, yöneticilerden toplanan veriler ve öğrencilerden toplanan veriler ayrı ayrı analiz edilmiştir. Verilerin analizinde şu sıra izlenmiştir.

1. Veriler tümüyle yazıldığı gibi bilgisayar ortamına geçirilmiştir.

2. Öğretmenlerin her bir soruya verdiği yanıtlar o sorunun altına, alt alta yazılmıştır. Benzer şekilde yöneticilerden toplanan cevaplar o sorunun altına, öğrencilerden toplanan yanitlar da cevabı verilen sorunun altına yazılmıştır.

3. Sorular altında toplanan cevaplar analiz edilerek benzer cevaplar aynı renklerle boyanarak gruplandırılmıştır.

4. Her grupta frekanslar en fazla vurgulanan konudan en aza doğru sıralanmıştır.

\section{Bulgular}

Çalışmadan elde edilen bulgular sırasıyla açıklanmıştır. 


\section{Öğretmenlerin Öğrencilerden Beklentilerine İlişkin Bulgular}

Öğretmenlerin öğrencilerden en çok derse hazırlıklı gelmeleri, derse aktif olarak katılmaları, dersin düzenini bozmamaları, kitap okumaları, verilen görevleri yerine getirmeleri ve sorumluluk sahibi bireyler olmaları şeklinde beklentileri olduğu görülmüştür. Öğretmenlerin öğrencilerden beklentileri Tablo 1'deki gibidir.

\section{Tablo 1. Öğretmenlerin öğrencilerden beklentileri}

\begin{tabular}{lll}
\hline Öğretmen Beklentisi & $\mathbf{f}$ & $\mathbf{\%}$ \\
\hline Derse katılım & 19 & 90.5 \\
\hline Derse ön hazırlık yaparak gelmesi & 18 & 85.7 \\
\hline Dersin huzurunu bozmaması & 17 & 81 \\
\hline Kitap okumaları & 17 & 81 \\
\hline Zamanlarını verimli kullanmaları & 16 & 76.2 \\
\hline Ödevlerini yapmaları & 15 & 71.4 \\
\hline Planlı çalısmaları & 15 & 71.4 \\
\hline Iyi not alma & 13 & 61.9 \\
\hline Sorumluluklarını bilen ve yerine getiren bireyler olmaları & 61.9 \\
\hline Kendilerini geliştirmeleri & 13 & 57.1 \\
\hline Planlı olmaları & 12 & 52.4 \\
\hline Kaliteli zaman geçirme & 11 & 38 \\
\hline Müzik dinlemeleri & 8 & 28.5 \\
\hline Sosyal olmaları & 6 & 23.8 \\
\hline Mutlu oldukları kişilerle zaman geçirmeleri & 5 & 19 \\
\hline Mutlu bireyler olmaları & 4 & 19 \\
\hline Motive gelmeleri & 4 & 14.3 \\
\hline Farkı kaynaklardan araştırma yapabilmeleri & 4 \\
\hline Öğretmenle göz teması kurma & 3 & 9.5 \\
\hline Çevreye ve hayvanlara duyarlı olmaları & 2 & 9.5 \\
\hline Düzenli spor yapmaları & 2 & 9.5 \\
\hline
\end{tabular}

Ayrıca öğretmenler; öğrencilerinin kendilerinden neler beklendiğinin farkında olduklarını düşündüklerini ifade etmiştir. Bu konuda Öğretmen3 şöyle ifade etmiştir.

"Bence öğrencilerimiz onlardan neler beklediğimizi biliyorlar. Çünkü her firsatta onlara söylüyoruz. Okul toplantılarnda, törenlerde söylüyoruz. Kendi adıma ben derslerde onlardan neler beklediğimi söylüyorum. Genelde sene başında ilk dersimizde dersin amaçlarl, benim onlardan beklentilerim neler söylüyorum. Derslerde de ara ara ihtiyaç duyduğumda söylüyorum."

Katılımcılardan yalnızca Öğretmen22 öğrencilerden beklentilerimizin neler olduğunu onlara tam olarak aktaramadıkları düşüncesindedir. 
“Öğrencilerimize esasında onlarm mutlu bireyler olabilmeleri için, sevdikleri mesleklere sahip olabilmeleri, kendilerini gerçekleştiren bireyler olabilmeleri için burada olduğumuzu, aslında öğrettiğimiz dersin konusundan, derste yaplan ders dişı sohbetlere kadar her şeyin, okuldaki tüm etkinliklerin onlarm gelecekte sahip olacakları değerlere katkısı olacak birer damlalar olduğunu anlatmıyoruz. Benim esas amacim dersin bir ünitesini ezbere söyleyebilmeleri değil, bu dersin alacaklarn iyi bir üniversite eğitimi, seçecekleri kendilerini mutlu edebilecek bir meslek için bir araç olduğunu bilmeleridir."

\section{Öğrenci Özelliklerine Göre Öğretmen Beklentilerine İlişkin Bulgular}

Öğrencilerinden beklentilerin, öğrencilerinin davranış, akademik/sosyal başarı gibi durumlarına göre değişip değişmediğine yönelik olarak öğretmenlerin büyük çoğunluğu beklentilerinin öğrenciden öğrenciye değiştiğini belirtmiştir. Katılımcı öğretmenler her öğrencinin ayrı ayrı değerlendirilmesi gerektiğine inanmaktadır. Katılımcıların büyük çoğunluğu (14, \%66) çalışkan ve etkili ders dinleyen öğrencilerine karşı sempati duyduklarını ve hem onlardan beklentilerinin daha yüksek olduğunu hem de onlarda gördükleri olumsuz davranışlara karşı daha toleranslı olduklarını belirtmiştir. Katılımcılardan Öğretmen27:

“Çalışkan ve etkili ders dinleyen, sorumluluklarmı zamanında yerine getiren öğrencilere karşı sempatim ister istemez oluyor. Bence her öğrenciyi ayrı ayr değerlendirmek gerekir, çünkü öğrenciler birbirinden farklı kişilik özelliklerinde. Dolayıstyla beklentilerim farklılaşıyor."

Bir diğer katılımcı ise (Öğretmen16) görüşlerini şöyle belirtmiştir:

"Başarlı öğrencilerimden beklentim yüksek oluyor. Bazı öğrencilerden hiçbir şey beklemiyorum. Olumlu tutum içerisinde olduğum öğrencimde olumsuz bir davranış gördüğümde bu beni oldukça şaşırtıyor, oysa davranış bozukluğu olan öğrencilerde ayn davranışı gördüğ̈̈mde şaşırmıyorum".

\section{Okul Yöneticilerin Öğrencilerden Beklentilerine İlişkin Bulgular}

Okul yöneticilerinin öğrencilerden en çok okul kurallarına uyan, başarılı, ahlaklı, erdemli, sorumluluklarının farkında olan bireyler olmaları şeklinde beklentileri olduğu görülmüştür (Tablo 2). 
Tablo 1. Okul yöneticilerinin öğrencilerden beklentileri

\begin{tabular}{lll}
\hline Yönetici Beklentisi & f & $\mathbf{\%}$ \\
\hline Okul kurallarına uymaları & 9 & 100 \\
\hline Derslerini düzenli ve sıkı takip etmeleri & 9 & 100 \\
\hline Milli ahlaki değerlere bağlı ve erdemli olmaları & 9 & 100 \\
\hline Sorumluluklarının farkında olmaları & 9 & 100 \\
\hline Arkadaşlarıyla iyi geçinmeleri & 7 & 77.7 \\
\hline Yeniliklere açık olmaları & 5 & 55.5 \\
\hline İetişimleri güçü olmalı & 5 & 55.5 \\
\hline Temiz düzenli ve disiplinli olmaları & 5 & 55.5 \\
\hline Üretken bireyler olmaları & 3 & 33.3 \\
\hline Sosyal ve yaratıcı bireyler olmaları & 2 & 22.2 \\
\hline Çevreye duyarlı olmaları & 2 & 22.2 \\
\hline Demokrasiyi özümsemeleri & 2 & 11.1 \\
\hline
\end{tabular}

\section{Öğrencilerinin Davranış, Akademik/Sosyal Başarı Gibi Durumlarna Göre Yönetici Beklentilerine İlişkin Bulgular}

Okul yöneticilerinin tamamının öğrencilerden beklentilerinin öğrenciden öğrenciye değiştiği bulgularına ulaşılmıştır. Bu konuda Yönetici3;

“Öğrenciler arasında ayrım yapmamaya çalışırım ancak sorumluluklarını yerine getiren, çalışkan öğrencilere karşı olumlu tutum geliştiriyorsunuz zamanla. Bu öğrencilerle, böyle olmayan öğrenciler arasında farkh beklentiler az da olsa oluşuyor. Bazı öğrenciler ne yaparsanız yapın sorumluluklarını hiçbir şekilde yerine getirmiyor. Bu öğrencilerden beklentiniz düşük oluyor." şeklinde ifade ederken Yönetici4;

"Bir okul müdürü olarak açıkçası akademik başarllarının yüksek olmasını beklerim. Çünkü öğrencilerin akademik başarısın yükseltmek okulumuzun esas görevidir. Okulumuz öğrencilerini bir üst öğrenime hazırlamak için var. Diğer kazanımlar bununla birlikte gelen kazanımlardır." şeklinde görüş bildirmiştir. Yönetici7;

"Ĕ̆itim verdiğimiz öğrenciler bilişsel ve duyuşsal olarak onlardan beklentilerimizin farkındalar. Onlardan beklentilerimizin neler olduğunu her firsatta onlara söylïyoruz. Davranışlarımızla da tutarlı olarak bu beklentilerimizi doğruluyoruz. Ben çeoreye duyarl bireyler olmalarn bekliyorum ve kendim de bu yönde projeler hazırlyyorum, ögrencilerimle birlikte bu tür projelerin içinde yer alıyorum." şeklinde ifade etmiştir. 


\section{Öğrencilerin Öğretmenlerinin Kendilerinden Beklentilerini Algılayış Biçim- lerine İlişkin Bulgular}

Öğrenciler, öğretmenlerin kendilerinden çoğunlukla derslere hazırlıklı gelmelerini, ders sırasında derse katılmalarını eğer derse katılmıyorlarsa konuşmadan sessiz durmalarını, dersi dikkatli dinlemelerini, çalışkan ve başarılı olmalarını beklediklerini belirtmişlerdir. Ayrıca öğretmenler kendilerinden iyi not almalarını, başarısız oldukları derslerde ise en azından geçer not almalarını beklediklerini belirtmişleridir (Tablo 3).

Tablo 2. Öğrencilerin öğretmen beklentilerine yönelik algılarn

\begin{tabular}{lll}
\hline Öğrenci algıları & $\mathbf{f}$ & $\mathbf{\%}$ \\
\hline Derse hazırlıklı gelme & 55 & 93.2 \\
\hline Derslerde konuşmadan uslu durma & 42 & 71.2 \\
\hline Derse katılım & 37 & 62.7 \\
\hline Başarılı olma & 34 & 57.6 \\
\hline Ders sonrasında tekrar yapma & 31 & 52.5 \\
\hline Dikkatli dinleme & 28 & 47.4 \\
\hline Çalışkan olma & 27 & 45.7 \\
\hline Ahlaklı saygilı olma & 17 & 28.8 \\
\hline Ödev yapma & 13 & 22 \\
\hline Rahatsız etmeme & 12 & 20.3 \\
\hline Test çözme & 11 & 18.6 \\
\hline Sosyal olma & 10 & 16.9 \\
\hline Araştırma yapma & 7 & 11.8 \\
\hline Düzenli olma & 6 & 10.1 \\
\hline Kaliteli zaman geçirme & 2 & 3.3 \\
\hline İyi not - geçer not alma & 1 & 1.6 \\
\hline
\end{tabular}

Öğrenciler, öğretmenlerinin genellikle derslerle ilgili beklentilerini sözlü olarak ifade ettiklerini aynı zamanda davranışlarıyla da beklentilerini belli ettiklerini belirtmişlerdir.

Ayrıca öğrenciler öğretmenlerinin beklentilerinin herkes için aynı olmadığını düşündüklerini ifade etmişlerdir. Bu konuda Öğrenci 41 şöyle ifade etmiştir:

“Öğretmenlerimiz çalışkan öğrencilerle daha çok ilgileniyor, o arkadaşlarımız hata yaptığında öğretmenlerimiz bizlere kızdığı gibi onlara kızmıyor. Onlara karşı daha anlayışlı ve sabırlı davranıyorlar. Oysa biz başarılı olmadığımız için bize karşı daha sinirli oluyorlar. Ĕ̆er biz de başarılı olsak öğretmenlerimizin bu beklentilerini yerine getirsek bize de farklı davranırlar." 


\section{Öğrencilerin Okul Yöneticilerinin Kendilerinden Beklentilerini Algılayış} Biçimlerine İlişkin Bulgular

Öğrencilerin, okul yöneticilerinin kendilerinden disiplinli olmalarını, okulun kurallarına uymalarını, çalışkan ve başarılı olmalarını, çevreye zarar vermemelerini, okula bağış yapmalarını, sigara içmemelerini beklediklerini belirtmişlerdir. Öğrencilerin ifadeleri Tablo 4 'te gösterilmektedir.

Tablo 3. Öğrencilerin okul yöneticilerinin kendilerinden beklentilerine yönelik algılar

\begin{tabular}{lll}
\hline Öğrenci algıları & $\mathbf{f}$ & $\mathbf{\%}$ \\
\hline Çalışkan ve başarılı olma & 34 & 57,6 \\
\hline Kurallara uyma & 22 & 37,2 \\
\hline Terbiyeli olma - saygılı olma & 16 & 27,1 \\
\hline Okul kıyafeti giyme -makyaj yapmama & 14 & 23,7 \\
\hline Disiplinli olma & 8 & 13,5 \\
\hline Temizlik & 8 & 13,5 \\
\hline Çevreye zarar vermeme & 7 & 11,8 \\
\hline Kavga etmeme & 4 & 6.7 \\
\hline Aidat & 3 & 5,1 \\
\hline Zamanı iyi kullanma & 1 & 1,7 \\
\hline Sigara içmeme & 1 & 1,7 \\
\hline
\end{tabular}

Bazı öğrenciler ise kendilerinin gelişimleriyle ilgili idarenin sorumlu olmadığını, idarenin kendilerinden başarı beklentilerinin olmadığını bu beklentinin ders öğretmenleri dışında okulun rehberlik birimi tarafından olduğunu belirtmişlerdir. Öğrenci 59; “Okul idaresi bizim derslerdeki başarılarımızla ilgilenmez. Yalnızca uslu durmamızı, aidatlarımızı ödememizi, problem çıkarmamamızı bekler. Derslerimizdeki durumumuzla ders öğretmenlerimiz ve rehber öğretmenlerimiz ilgilenir." şeklinde ifade etmiştir.

\section{Tartışma ve Sonuç}

Araştırmada, öğretmenlerin öğrencilerden en çok derse hazırlıklı gelmeleri, derse aktif olarak katılmaları, dersin düzenini bozmamaları, kitap okumaları, verilen görevleri yerine getirmeleri ve sorumluluk sahibi bireyler olmaları şeklinde beklentileri olduğu görülmüştür. Öğretmenlerin büyük çoğunluğu beklentilerinin öğrenciden öğrenciye değiştiğini belirtmiştir. Bu bulgular önceki araştırmaların bulgularıyla tutarlık göstermektedir (Rosenthal ve Jacobson, 1968; Brophy ve Good,1969; Tatar, 2014; Öztürk vd., 2002a-2002b). Okul yöneticilerinin öğrencilerden en çok okul kurallarına uyan, başarill, ahlaklı, erdemli, sorumluluklarının farkında olan bireyler olmaları şeklinde beklentileri olduğu görülmüştür. Okul yöneticilerinin tamamının öğrenciler- 
den beklentilerinin öğrenciden öğrenciye değiştiği bulgularına ulaşılmıştır. Öğretmenler ve yöneticiler öğrencilerden neler beklediklerini onlara söylediklerini davranışlarıyla da bu beklentilerini onayladıklarını belirtmişlerdir. Ö̆̆retmenlerin ve yöneticilerin büyük çoğunluğu öğrencilerden beklentilerinin öğrenciden öğrenciye değiştiğini belirtmiştir. Bu bulgular Öztürk, Şahin ve Koç'un (2002b) araştırmasının öğretmenlerin yüksek ve düşük beklenti geliştirmede öğrenci özelliklerinden etkilendiği yönündeki bulgularıyla da örtüşmektedir. Öğrenciler ise öğretmenlerin kendilerinden çalışkan ve başarılı olmalarını, derslere hazırlıklı gelmelerini, ders sırasında derse katılmalarını eğer derse katılmıyorlarsa konuşmadan sessiz durmalarını beklediklerini belirtmişlerdir. Ayrıca öğretmenler kendilerinden iyi not almalarını, başarısız oldukları derslerde ise en azından geçer not almalarını beklediklerini belirtmişleridir. İdarecilerin kendilerinden disiplinli olmalarını, okulun kurallarına uymalarını, çalışkan ve başarılı olmalarını, çevreye zarar vermemelerini, okula bağış yapmalarını, sigara içmemelerini beklediklerini belirtmişlerdir. Bazı öğrenciler ise kendilerinin gelişimleriyle ilgili idarenin sorumlu olmadığını, idarenin kendilerinden başarı beklentilerinin olmadığın bu beklentinin ders öğretmenleri dışında okulun rehberlik birimi tarafından olduğunu belirtmişlerdir. Öğrencilerin kendilerinden derse hazırlıklı gelme, ders içi davranış, akademik başarı gibi beklentilerin farkında oldukları; ancak öğretmenlerin ve okul yöneticilerinin belirttiği çevreye ve hayvanlara duyarlı olmaları, mutlu birey olmaları gibi beklentilerin farkında olmadıkları görülmüştür. Buradan hareketle eğitim sisteminin en önemli öğesi olan öğrencilerin; öğretmenlerinin ve okul idaresinin kendilerinden beklentilerine yönelik algılarının öğretmen ve yöneticilerin gerçek beklentileriyle çoğunlukla tutarlık gösterdiği söylenebilir. Brophy (1983) de öğretmenlere, öğrencilerinin öğrenme konusundaki kendi heyecanların paylaştıklarına yönelik tutum, inanç ve beklentileri göstermelerini tavsiye etmektedir. Merton (1948) da öğrencilerin öğretmenlerinin kendilerinden ne beklediklerinin farkında olması ve buna göre davranış sergilemesinin beklenti etkisi yarattığını ifade etmektedir. Öğretmenin bu etkinin farkında olması öğrencilerin gelişimleri için önemli görülmektedir. Yanlış tutumlar sonucunda geliştirilen beklentiler gerçekten başarmaya çalışan bir öğrenciyi olumsuz etkilemektedir. Öğretmenler öğrencilerden beklentilerinin öğrenciler tarafından anlaşıldığının farkında olmalı bu nedenle de öğrencilere yönelik sürekli olumlu beklenti geliştirmeli ve öğrenciye de bunu doğru aktarmalıdır. 


\title{
EXTENDED ABSTRACT
}

\section{Managers' and Teachers' Expectations from Students and Students' Perception of These Expectations}

\author{
* \\ Şefika Şule Erçetin - Sait Akbaşl1 - Ercan Baysülen \\ Ministry Of National Education, Hacettepe University
}

In this study, it is aimed to determine what the expectations of teachers and school administrators are from students and how these expectations are perceived by secondary school students. The main question of this research can be expressed as "What are the expectations of the administrators and teachers from the students and how the students perceive these expectations?" The following sub-problems were also sought:

1. What are the teachers' expectations from the students?

2. Do teachers 'expectations vary according to their students' behavior, academic / social achievement?

3. What are the school administrators' expectations from the students?

4. Do the expectations of school principals vary according to their students' behavior, academic / social achievement?

5. How do students perceive their teachers' expectations?

6. How do students perceive school administrators' expectations from themselves?

This study was conducted by using qualitative research. The study was conducted in the 2018-2019 academic year. The study group of the study consists of 59 students, in 9.10,11 and 12th grades, 21 teachers and 9 administrators in a public school in Bayraklı District of İzmir Province. Semi-structured interview forms consisting of open-ended questions were used to determine the views of the participants. The interview forms were arranged in line with the opinions of three experts and took their final form. The researchers interviewed all participants face to face. Interviews lasted between 5 minutes and 20 minutes. In the research, content analysis method, one of the qualitative data analysis techniques, was used in the analysis of the views of teachers, administrators and students. 
Results: It was seen that teachers had expectation of students to come prepared for the lesson, to participate actively in the lesson, not to disrupt the order of the lesson, to read books, to fulfill the assigned tasks and to be responsible individuals. The majority of teachers stated that their expectations vary from student to student. It was seen that the school administrators had the expectations of students to be successful, moral, virtuous and aware of their responsibilities. It was found that the expectations of the school administrators changed from student to student. Teachers and administrators stated that they told them what they expected from the students and that they confirmed their expectations with their behavior. The majority of teachers and administrators stated that their expectations from students vary from student to student. These findings are consistent with the findings of Öztürk, Şahin and Koç (2002b) that teachers are affected by student characteristics in developing high and low expectations. The students stated that their teachers expected to be hardworking and successful, to come prepared for the lessons, to participate in the lesson and to remain silent without speaking if they did not attend the lesson. In addition, the teachers stated that they expect them to get good grades and at least pass the grades in the courses they fail. They stated that the administrators expected them, to be disciplined, to follow the rules of the school, to be hardworking and successful, not to harm the environment, to donate to the school and not to smoke. Some students stated that the administration is not responsible for their own social and academical development, that the administration does not have any expectations of success from them and that this expectation is provided by the guidance unit of the school. The one of the important findings of the study is; the students are aware of the expectations, such as coming prepared for the lesson, academic success; however, they were not aware of expectations from them such as being sensitive to the environment and animals and being happy individuals.

\section{Kaynakça / References}

Brophy, J. E. (1983). Research on the self-fulfilling prophecy and teacher expectations. Journal of Educational Psychology, 75(5), 631-661. 
Brophy, J. E. (1998). Introduction. J. E. Brophy (Ed.), Advences in research on teaching: Expectations in the classroom, 7, ix-xvii, Greenwich, CT: Jai Press Inc.

Brophy, J. E., ve Good, T. L. (1969). Teachers' communication of differential expectations for children's classroom performance: Some behavioral data. Journal of Educational Psychology, 61(5), 365-374. https://doi.org/10.1037/h0029908

Harris, M. J., Milich, R. ve McAninch, C. B. (1998). When stigma becomes self-fulfilling prophecy: Expectancy Effects and the causes, consequences, and treatment of peer rejection. J. Brophy (Ed.), Vol. 7, Advences in Research on Teaching: Expectation in the Classroom., London: Ja1 Press Inc.

Merton, R. K. (1948). The self-fulfilling prophecy. Antioch Review, 8, 193-210.

Öztürk, B., Koç, G., ve Şahin, F. T. (2002a). Sinıf öğretmenlerinin yüksek ve düşük beklenti geliştirdikleri öğrencilere yönelik davranışlarının farkıllaşma durumu. eğitim bilimleri ve uygulama, 1(2), 161-181.

Öztürk, B., Şahin, F. T., ve Koç, G. (2002b). İlköğretim okullarında öğretmen beklentilerini etkileyen öğrenci davranışları. Eğitim Yönetimi, 390-413.

Tatar, A. (2014). Öğretmen beklentisi. Yüzüncü Yıl Üniversitesi Eğitim Fakültesi Dergisi, 2 (2).

Weinstein, R. S. ve Mckown, C. ; (1998), Expectancy effects in 'context': Listening to the voices of students and teachers. J. Brophy (Ed.), Vol 7, Advences in Research on Teaching: Expectations in the Classroom, London:Jai Press Inc..

Yıldırım, A. ve Şimşek, H. (2006). Sosyal bilimlerde nitel araştırma yöntemleri. Ankara: Seçkin.

\section{Kaynakça Bilgisi / Citation Information}

Erçetin, Ş.Ş. ve Akbaşlı, S. ve Baysülen, E. (2020). Yönetici ve öğretmenlerin öğrencilerden beklentileri ve öğrencilerin bu beklentileri algılayış biçimleri . OPUS-Uluslararası Toplum Araştırmaları Dergisi, 16(Eğitim ve Toplum Özel Sayıs1), 5941-5954. DOI: 10.26466/opus.705266 